\title{
Derrida e Jean-Luc Nancy: leituras da ex-propriação
}

\author{
Luiz Henrique Carvalho Penido
}

Mestre em Letras: Estudos Literários pela UFMG, Doutorando em Letras: Literatura Comparada / UFMG.

\begin{abstract}
RESUMO
A proposta do presente texto é debater a herança de Jacques Derrida sob o signo da ex-propriação: movimento para fora do proprius, gesto para além do pertencimento e da adequação de um “para si”. Para demonstrar a relevância de um ato de leitura ex-propriado pretendemos analisar tais gestos em uma das figuras mais eminentes de sua herança: Jean-Luc Nancy.
\end{abstract}

\section{PALAVRAS-CHAVE}

Ex-propriação, herança, ato de leitura

\begin{abstract}
A “essência” da presença está em sua existência. As características que podem extrair deste ente não são, portanto, "propriedades" simplesmente dadas de um ente simplesmente dado que possui esta ou aquela “configuração”. As características constitutivas da presença são sempre modos possíveis de ser e somente isso. Toda modalidade de ser deste ente é primordialmente ser. Por isso, o termo "presença”, reservado para designá-lo, não exprime a sua quididade como mesa, casa, árvore, mas sim o ser.
\end{abstract}

Heidegger. Ser e tempo.

A citação de Heidegger, como voz que antecede o que aqui pretendemos dizer, surge segundo a necessidade de traçar um plano de imanência fluido o suficiente para articular algumas observações a propósito de dois escritores contemporâneos - refirome a Jacques Derrida e Jean-Luc Nancy - , que, implícita ou explicitamente, atribuem a produtividade de seus escritos a certo legado heideggeriano, mais especificamente ao que ele clama por tarefa de sua filosofia: a rememoração ou restituição do ser. Por ora, lembremos o essencial da tarefa heideggeriana, a saber: uma vez que toda a metafísica 
se converteu em onto-teo-logia, é preciso traçar os limites dessa conversão e a analítica desse esquecimento. Mais ainda, é preciso caminhar fora dos esquematismos ou das taxinomias - redução do ser às categorias limitantes do ser supremo e do ente mais geral, como é pensado pela metafísica desde os gregos e com maior ênfase após o advento do cristianismo - para engendrar em todas as suas dimensões uma "ontologia fundamental” que só pode ser a destruição da onto-teo-logia.

Não desejamos e nem temos por fim apresentar a envergadura do problema a que Heidegger se propõe analisar; este artigo pretende apenas fazer notar alguns traços que atravessam a tarefa heideggeriana para, então, articular tais traços àquilo que Derrida chamou différance, e que, posteriormente, Jean-Luc Nancy reintroduziu sob o nome de experiência da liberdade. Nossa hipótese é de que a originalidade da questão heideggeriana do ser subsume excepcionalmente tanto o plano de uma economia geral da différance - grande eixo de entrada no texto de Derrida -, quanto a experiência da liberdade em seu limite - tarefa-risco na filosofia de Jean-Luc Nancy.

Sendo assim, é preciso, primeiro, elaborar, ainda que provisoriamente, os traços mais significativos do projeto heideggeriano, mais especificamente, o modo como a tarefa da elaboração da questão do ser enraíza algumas possibilidades que, retomadas pelos autores em questão, dão a feição de uma leitura-escrita ex-propriada. Por expropriação, entendemos esse movimento para fora do proprius, isto é, movimento que, no ato mesmo de apropriação daquilo que é o seu sentido mais próprio, é solapado, desfundamentado, ex-localizado. Não se trata de um embate na forma da dialética entre o gesto que apropria e a linha de fuga que faz esse gesto deslizar - nesse caso, a questão giraria entre o próprio e o impróprio -, mas de uma ex-timidade de qualquer pertencimento e de qualquer presença. Mais adiante isso ficará mais claro; por ora, voltemos a Heidegger.

Quando Heidegger inaugura a questão do ser, ele o faz por um gesto original, declarando, como foi mencionado na epígrafe deste texto, que “A 'essência' da presença [ser-aí/Dasein] está em sua existência”. ${ }^{1}$ Ora, se a questão do ser é a história de um esquecimento, isso se deve primeiramente ao fato de que o ser foi sempre pensado essencialmente como separado de sua existência, isto é, os essencialismos e existencialismos agregaram um espaçamento inerte como diferença entre essência e existência - o exemplo mais recente seria Sartre na célebre afirmação de que a

\footnotetext{
${ }^{1}$ HEIDEGGER. Ser e tempo, p. 48.
} 
existência precede a essência. Em contraposição à diferença passiva, Heidegger inaugura a forma quiasmática da questão pela introdução do termo Da-sein, ou ser-aí, operando o primeiro des-fundamento na tarefa de destruição da onto-teo-logia, pois o $D a$ significa o ser enquanto essencial abertura. Para Heidegger, “ $D a$ quer dizer 'aqui’ ou 'lá' (...) 'aqui' ou 'lá' são possíveis apenas em um $D a$, ou seja, somente se existe um ente que, como ser do $D a$, abriu a sua espacialidade.” 2 A abertura que nasce da inclusão desse $D a$ só se torna possível, justamente, no quiasma, que representa a junção da essência como sua própria existência. O quiasma exclui qualquer possibilidade de limitação conceitual ou atributiva do sein, que passa a ser aquilo que indica o $D a$; mais ainda, o próprio do ser é que seja essa indicação muda do seu $D a$, pois “na sua ausência, ele [o ser] não somente não existiria de fato, mas não poderia ser, em geral, o ente desta essência. O Dasein é a sua abertura.” 3

O primeiro aspecto concernente à chave que representa o Dasein na reflexão heideggeriana de uma ontologia fundamental articula-se agora a uma segunda linha de força: a tarefa sempre retomada, implícita em Ser e o tempo, obsessiva nos escritos posteriores que se confiavam ao problema da linguagem, de trazer a linguagem como linguagem para a linguagem; em outras palavras, trazer à linguagem sua fala. Para Heidegger, há um equívoco ao se considerar a linguagem segundo as representações tradicionais de "energia, atividade, trabalho, força do espírito, visão de mundo, expressão". Tomando tais termos por fundamento, a linguagem é alinhada a conceitos e não à linguagem ela mesma; esquece-se a fala da própria linguagem para demorar-se sobre o dito da linguagem como metalinguagem, como reflexão lógico-gramatical espraiada na superfície do discurso. Para contornar esse equívoco, ele propõe a busca do vigor da linguagem sob o nome de rasgadura. "Riss, rasgo, é a mesma palavra que ritzen, riscar, arranhar. (...) A rasgadura é o todo dos rasgos daquele riscado que articula o entreaberto e o livre da linguagem.”“ Novamente nos vemos, com a unidade da rasgadura, voltados para o Dasein, uma vez que o rasgo vislumbra a abertura como momento em que o que se fala e o que não se fala articulam-se e algo vem à linguagem pela proveniência desse rasgo. Esse algo que vem à linguagem na forma da rasgadura é a fala da linguagem; em outras palavras, é exatamente porque a rasgadura abre o sulco e

\footnotetext{
${ }^{2}$ HEIDEGGER. Ser e tempo, p. 191.

${ }^{3}$ HEIDEGGER. Ser e tempo, p. 192.

${ }^{4}$ HEIDEGGER. A caminho da linguagem, p. 201.
} 
articula tanto o que se fala quanto o que não se fala - esse reclamado da fala que sobrevém como indício, no sentido de uma remissão - que podemos, segundo nos afirma Heidegger, nos aproximar decisivamente, na saga do dizer, da linguagem como linguagem.

Interessante é observar que, por caminhos semelhantes, chegamos à tarefa de uma destruição da onto-teo-logia, tendo por operador tanto o Dasein, quanto a fala da própria linguagem na rasgadura. Não seria inadequado pensar que o que Heidegger chama de rasgadura se articula ao Dasein da seguinte forma: assim como o Dasein, o ser-aí é a abertura essencial, sem a qual o ser em geral sequer existiria enquanto ente, a rasgadura, como operadora da aproximação da fala da linguagem, é, de forma semelhante, o sulco que entreabre, que liberta a linguagem, bem como estabelece a sua condição de possibilidade. Em outros termos, tanto na ontologia fundamental do Dasein quanto no seu desenvolvimento necessário nas reflexões da fala da linguagem, trata-se de visualizar determinada experiência do não fechamento e da disseminação. $O$ elemento de uma tal reflexão é a força ex-propriadora presente no gesto mesmo de apropriação, pois o Dasein é tanto a possibilidade inscrita de ser-o-aí, ou seja, de estarse no próprio lugar, quanto o mostrar-se inatual de toda enunciação do ser no momento do dizer, um shifter, digamos, que carrega simultaneamente o poder ter lugar e o impoder da pura negatividade. Do mesmo modo, o gesto de apropriação da fala da linguagem expropria-se no momento da rasgadura, pois esta, como conjunção entre o que se fala e o que não se fala, realiza o jogo impossível do mostrar-se ausente e ocultar-se presente que é o seu gesto próprio na aproximação da fala da linguagem. Nesse sentido, a rasgadura faz do rasgo a remissão infinita entre o que se fala e o que não se fala, a verdadeira revelação da fala da linguagem: a linguagem fala essa forma quiasmática do dizer e do não dito, que se corremetem.

Com essas duas linhas de força da tarefa heideggeriana, podemos, sem dúvida, ouvir melhor os ecos de um texto seminal da reflexão contemporânea: trata-se do texto “La différance”, de Jacques Derrida, em todas as suas implicações nostálgicas de uma esperança heideggeriana, como o próprio autor admite. É preciso, por essa via, indicar em que o Dasein e a fala da linguagem como rasgadura podem ecoar na palavra ou conceito de différance, esse maugrafismo pleno de possibilidades que não é, essencialmente, nem uma palavra, nem um conceito. Em primeiro lugar, observemos que um $a$ silencioso marca a grafia de différance, letra que se escreve, mas não se escuta, permanecendo silenciosa ali mesmo onde produz diferença. O a de différance 
marca o enclausuramento de um antigo preconceito, o da escritura fonética. Não há, de fato, escritura puramente e rigorosamente fonética, na medida em que, permanecendo como traço áfono, tal escritura não pôde e não pode funcionar. É preciso admitir que, desde sempre, a escritura fonética trabalhou com traços não fonéticos, ou ainda, que a condição de funcionamento de toda escritura fonética está em traços não presentes em si mesmos ou não apresentados em si mesmos. Em uma esfera metafísica, na qual a escritura dita fonética articula-se como presente em si mesma, o a silencioso introduz uma pequena anarquia que desequilibra o sendo presente da phoné e o coloca sob a extensão de uma negatividade não nomeada, subsumida na abertura da différance a algo que a con-tém.

Ora, muito facilmente nos colocamos aqui no caminho aberto pela ontologia fundamental; o Da do Dasein, esse "aqui”, “ali” que funciona como o shifter de uma diferença, pode ser reencontrado no a silencioso da différance. O próprio do Dasein é que ele marque essa presença como ausência no ato mesmo de a indicar, ser-aí que, exatamente no momento de apresentar-se, é ex-propriado do gesto indicador do ser em si mesmo, contraindo uma dívida com aquilo que traça a sua condição de possibilidade. O a da différance, marcando a afonia da escritura fonética, abre o termo para aquilo que desde sempre foi a condição da escritura em geral, digamos, usando outro termo derridiano, a arqui-escritura, como unidade não originária (porque áfona e ágrafa) da escritura e da fala em geral. É nesse sentido que podemos entender a afirmação de que

\footnotetext{
A différance é não somente irredutível a toda reapropriação ontológica ou teológica - onto-teológica - mas, abrindo o espaço mesmo no qual a onto-teologia - a filosofia - produz seu sistema e sua história, ela a compreende, a inscreve e a excede sem retorno. ${ }^{5}$
}

Assim como Dasein, a différance não pode ser um termo positivo no qual se acumulariam os atributos de uma modalidade do ser; pelo contrário, ela deve funcionar como o movimento em si mesmo ausente que arrasta os efeitos de atribuição, nomeação, as concreções verbais ou nominais, feixes ou efeitos de síntese.

Mas différance carrega ainda um outro sentido, sem dúvida mais concreto, na medida em que se apoia em determinada iniciativa da linguística estrutural de Saussure. Para ele, o signo apresenta dois motivos principais: a arbitrariedade e o caráter diferencial. Os dois motivos se articulam na medida em que a arbitrariedade do signo

\footnotetext{
${ }^{5}$ DERRIDA. Marges: de la philosophie, p. 6. (tradução nossa)
} 
indica o funcionamento da linguagem como puro sistema de diferenças, isto é, uma vez que o signo é não motivado, para sustentar-se, a linguagem articula-se sistematicamente em uma rede de diferenças em que não há termos positivos, em que jamais um termo está presente em si mesmo. A linguagem como sistema de diferenças tem por consequência a não pertinência da própria ideia de signo; portanto, só haverá diferenças e diferenças de diferenças, sendo a différance "a possibilidade da conceitualidade, do processo e do sistema conceitual em geral”. ${ }^{6}$

O que Derrida retoma é, sem dúvida, a tarefa tardia de Heidegger: a condição para que fale na linguagem a própria linguagem, novamente a esperança heideggeriana de que no entreaberto da rasgadura fale a linguagem ela mesma. Projeto, como percebemos em Derrida, solapado pelo próprio funcionamento da rasgadura, do traço em geral, em que o reclamado da fala sobrevém como indício em uma remissão infinita. A saga do dizer é já sempre uma ex-propriação do dito que diz o dizer, mas que, subsumido nessa mesma estrutura, traça a possibilidade do dizer em geral. É exatamente por isso que Derrida associa o a silencioso da différance à economia da morte:

O a da différance não se escuta, ele permanece silencioso, secreto e discreto como um túmulo: oikesis. Marquemos, assim, por antecipação, esse lugar, residência familiar e túmulo do próprio onde se produz em diferença a economia da morte. ${ }^{7}$

Que a linguagem esteja inscrita em uma economia da morte, é tema recorrente e aparece em vários autores - particularmente no próprio Heidegger, no qual o homem figura como o animal que possui a faculdade da linguagem e a faculdade da morte, a sua especificidade. Mais importante é perceber como uma tal economia funciona sob a forma geral de uma ex-propriação fundante, ou fundamental, com as restrições do pertencimento à linguagem da metafísica que nos fazem essas palavras. A retomada da tarefa heideggeriana em Derrida forma o esboço geral de uma questão sobre o lugar daquele que é aquilo que não é, aquele que não pode confiar-se em si mesmo - o Dasein - e aquele que não pode falar o que fala o seu dizer - a fala da linguagem -, dois ritmos ou pontos focais da ex-propriação como tema deste artigo.

Poderíamos nos perguntar agora como os ardis da ex-propriação - esse tema geral que coordenou os pontos de interesse aqui - nos evocam ou nos familiarizam com determinada tarefa do pensamento para além das proposições particulares. É sobre esse

\footnotetext{
${ }^{6}$ DERRIDA. Marges: de la philosophie, p. 11. (tradução nossa)

${ }^{7}$ DERRIDA. Marges: de la philosophie, p. 4. (tradução nossa)
} 
campo de questões que desejamos inscrever o pensamento nos limites da experiência da liberdade como ela aparece em Jean-Luc Nancy, e como entrelaça-se às práticas mais essenciais de Derrida e Heidegger. Em primeiro lugar, o que significa pensar em relação a essa liberdade? O que significa, implicada nas condições de possibilidade de todo pensamento, a liberdade ou o pensar livre? Ora, se, como demonstramos, tanto Derrida quanto Heidegger arriscam forçar o pensamento para termos liminares, não conceitos, proliferando os espaços quiasmáticos, é preciso que também a palavra "liberdade” não designe nem uma essência, servindo de fundamento aos agenciamentos de um saber centrado, nem se refira a liberdades particulares, "existências”, pequenos consentimentos pontuais.

Nem essência, nem existência, mas a dinâmica de sua irredutibilidade - como o Dasein, em sua indicialidade faltante, ou a différance, pela atração desse $a$ silencioso. A consequência é que a experiência da liberdade se converta no abandono, na liberdade do abandono que advém do fato de a existência se constituir a si própria como essência, primeira das notas aqui reunidas:

Porque a liberdade não pode ser nem "essencial", nem "existencial", mas implicada no quiasmo desses conceitos: é preciso pensar isso que faz a existência, em sua essência, abandonada a uma liberdade, livre para esse abandono, liberta em si e em si disponível. ${ }^{8}$

Tendo esse abandono em mente, podemos pensar que a experiência da liberdade é a própria condição de possibilidade do ser-aí segundo uma generosidade ontológica: “a essência da liberdade não é propriamente vislumbrada somente uma vez que a procuramos, a liberdade, mas enquanto funda a possibilidade do ser-aí [Dasein].”9 Somos já e desde sempre livres, abandonados a essa liberdade, e por ela abrimo-nos ao verdadeiro sentido do Dasein.

Parece que a experiência ex-propriadora, se quisermos estar com e em relação a Heidegger, Derrida e Nancy, focos de interesse aqui, é o desafio de nosso tempo, na medida em que ajusta o ser ao índice de um jogo irredutível à simples presença-ausência (Dasein), a liberdade à ex-propriação, a linguagem à tarefa infinita e sempre solapada de sua fala. Resta-nos, agora, assumir a liberdade na ex-propriação que é pensar a própria possibilidade de pensar - não como epistemologia, mas como jogo -, indiferentemente se chamarmos a essa experiência de Dasein, fala da linguagem, ou

\footnotetext{
${ }^{8}$ NANCY. L'expérience de la liberté, p. 13. (tradução nossa)

${ }^{9}$ NANCY. L'expérience de la liberté, p. 55. (tradução nossa)
} 
experiência da liberdade. Ainda ecoando Heidegger, nossa condição in-condicionada, nossa obstinação insuperável em atingirmos o ser do Dasein, momento em que nos tomaríamos por aquilo que somos, revela, contrariamente, a nossa própria falta de fundamento, nos relega a tarefa infinita no lugar mesmo em que já estamos.

\section{RESUMÉ}

Le texte a pour objectif le débat sur l’héritage de Jacques Derrida sous le signe de l'ex-propriation: mouvement de sortie du proprius, geste au-delà du appartenant et de l'adéquation d'un "pour-soi". Pour démontrer la pertinence d'un acte de lecture exproprié, nous avons l'intention de analyser ceux actes à l'un des plus éminentes figures à l’héritage de Derrida: Jean-Luc Nancy.

\section{MOTS-CLÉS}

Ex-propriation, héritage, acte de lecture

\section{REFERENNCIAS}

DERRIDA, Jacques. Marges: de la philosophie. Paris: Les Éditions de Minuit, 1967.

DERRIDA, Jacques. A escritura e a diferença. Trad. Maria Beatriz Marques Nizza da Silva. São Paulo: Perspectiva, 2002.

HEIDEGGER, Martin. Ser e tempo. Trad. Márcia Sá Cavalcante Schuback. 3. ed. Petrópolis: Vozes, 2008.

HEIDEGGER, Martin. A caminho da linguagem. Trad. Emmanuel Carneiro Leão; Gilvan Vogel e Márcia Sá Cavalcante Schuback. 2. ed. Petrópolis: Vozes, 2003.

NANCY, Jean-Luc. L’expérience de la liberté. Paris: Éditions Galilée, 1988. 